\title{
An assessment of child care facility playground surfacing safety in Calgary, Alberta
}

\author{
Dana East ${ }^{*}$, Karla Gustafson ${ }^{\dagger}$, Jason Cabaj ${ }^{\ddagger}$, and Lynne Navratill \\ * Executive Officer, Environmental Public Health, Alberta Health Services, 10101 Southport Road SW, Calgary, Alberta T2W 3N2 \\ ${ }^{\dagger}$ Medical Officer of Health, Alberta Health Services, Calgary Zone, 10301 Southport Lane SW, Calgary, Alberta T2W 1S7 \\ ${ }^{\ddagger}$ Medical Officer of Health, Alberta Health Services, Calgary Zone, Assistant Clinical Professor, Community Health Sciences, University of Calgary \\ Program Director, Public Health \& Preventive Medicine, University of Calgary, 10301 Southport Lane SW, Calgary, Alberta T2W 1S7 \\ " Director, Environmental Public Health, Calgary Zone, Alberta Health Services, 10101 Southport Road SW, Calgary, Alberta T2W 3N2
}

\begin{abstract}
Absorption capacity of playground surfaces is a well-recognized factor in injury prevention as most playground injuries result from falls on playground surfaces. In the past, Environmental Health Officers had no way of evaluating impact absorption of playground surfaces so injury prevention capacities of surfacing were unknown. To assess injury prevention characteristics of playground surfaces in the Calgary Zone, Environmental Public Health began testing surfaces in 2012 with a Triax Surface Impact Tester. A total of 102 playground surfaces were tested to the end of 2016. Forty-five (44\%) playgrounds failed the impact absorption test, indicating falls from the equipment onto these surfaces could result in a life-threatening head injury. These findings suggest a large percentage of playground surfaces are not providing adequate fall safety. Playground owners/operators require additional knowledge and resources to inform decisions about playground surfacing, and changes to public health legislation should be considered to require formal assessment of playgrounds and ensure playground surfacing is addressed in a consistent manner.
\end{abstract}

Keywords: Playground surfacing, Triax testing, injury prevention

Active outdoor play contributes immeasurably to children's health, well-being, and overall development (Fuselli and Yanchar, 2012) and play is recognized as a child's right by United Nations member parties (United Nations General Assembly, 1989). Playgrounds offer a place for children to play and develop skills, but they are also a common location of injury (MacKay, 2003 ) with the majority (up to 70\%) of playground injuries resulting from falls on playground surfaces (Briss et al., 1995). In Alberta, emergency department visits due to playground equipment falls for children 1-14 years of age increased from 4,221 (666 per 100,000) in 2010 to 6,864 (962 per 100,000) in 2015 (Alberta Health, 2016). A variety of factors contributing to playground injuries from falls have been identified in the literature including playground characteristics, child characteristics, supervision, equipment maintenance, and environmental conditions (Laforest et al., 2001). Although definitive data on which factors are the most important predictors of injury is lacking, absorption capacity of playground surfaces is one well-recognized playground characteristic in fall-related injury (Howard et al., 2009).

Improving surfaces has the potential to reduce a spectrum of injuries from those that are nonsevere and common to traumatic brain injury and death, which fortunately occur rarely (Cheng et al.,

Corresponding author: Dana East (email: Dana.East@ahs.ca)
2016; Gunatilaka et al., 2004). Environmental Health Officers (EHOs) in Alberta, who are injury prevention advocates and are responsible for inspecting playgrounds used by licensed child care programs, have experienced difficulty inspecting and evaluating surfacing due both to lack of records and information maintained by playground owners and the absence of a simple method to determine if impact absorption is sufficient. Assessing impact absorption is particularly challenging for unitary surfacing materials such as rubber tiles, rubber pour-in-place, and artificial grass turf. Alberta Health Services Environmental Public Health (EPH) investigated methods to test the impact absorption of playground surfacing and carried out a pilot project using a computerized portable test device called the Triax Surface Impact Tester, which provides Gmax (multiple of $\mathrm{g}$ - the rate of acceleration due to gravity, $9.8 \mathrm{~m} / \mathrm{s}^{2}$-that represents the maximum acceleration experienced during an impact) and Head Injury Criterion (HIC-a measure of impact severity that takes into consideration the duration over which the most critical section of the deceleration pulse persists, as well as the peak level of that deceleration (CSA, 2014)) readings required by the CSA Z614 Standard to measure impact absorption. The goal of this research was to determine the state of playground surfaces in a representative number of child care facilities as well as identify those with imminent hazards in hopes to minimize the likelihood of life threating head injuries sustained from falls. 


\section{Methods}

In 2012, Calgary Zone EPH purchased a Triax 2010 Surface Impact Tester and EHOs attended a training course leading to certification in the operation of the Triax 2010 Surface Impact Tester by the Canadian Playground Advisory Inc. EHOs have continued testing child care facility playgrounds in the Calgary Zone with the Triax Surface Impact Tester through 2016 and a variety of surfacing materials have been tested (see Table 1). Values provided in the Canadian Standards Association (CSA) Standard for Children's Playspaces and Equipment 2014 are used to determine whether a surface will pass the impact absorption test, defined as prevention of a life-threatening head injury. Specifically, to prevent a life-threatening injury to the head, the drop test must have a maximum deceleration experienced during impact (Gmax) not more than 200 and an HIC measure not in excess of 1000 when tested for the defined fall height of the play equipment (CSA, 2014). All playgrounds were tested using drop heights of the platform, the designated fall height of the equipment (CSA, 2014), and the highest climbable point on the play structure (if different than the designated fall height). All playgrounds were tested using a standard test method (American Society for Testing and Materials, 2013), which has been adopted as the approved test method by CSA. All testing was completed according to 2014 CSA criteria (which are unchanged from criteria found in the CSA 2007 standard). The verification method stipulated by the manufacturer of the Triax 2010 device was followed to ensure the instrument was working properly between factory calibrations. The device was verified each week the testing was done. Verification was completed by conducting drop tests on a standard rubber mat at a consistent drop height and compared with results that were provided by the manufacturer.

\section{Results}

From 2012 to 2016, a total of 102 playground surfaces were tested at different licensed child care facilities in Calgary, with 45 of these playground surfaces (44\%) failing the impact absorption test indicating that falls from the equipment onto these surfaces could result in severe head injury (Table 1). Loose fill materials were not a focus for testing since most child care facilities have rubber tile or pour-in-place surfacing. These materials were tested as a priority since there is no means to measure impact absorption other than doing a surface impact test. With loose fill materials, inspectors can reference Table D.2 in the CSA-Z614 Standard to determine if impact absorption is reasonable. Table D.2 lists various types of loose fill materials and provides recommended depths for different types of loose fill materials based on the critical height of the play equipment. There is no similar table provided for pour-in-place or rubber tiles since the materials vary depending on the manufacturing process and expected life span.

\section{Discussion and challenges}

Impact absorption testing of playground surfaces is not a requirement of public health legislation in Alberta and, while Calgary Zone EPH continues to test child care facility playgrounds, the other four geographic health regions in Alberta do not have access to a Triax Surface Impact Tester.

All types of playground surfacing can pass Triax testing if installed and maintained properly. Significant variation was seen with rubber tiles; in some failed tests, tiles were not purchased from a reputable source, were not manufactured to be playground tiles, or were installed improperly. Many of the tiles passed from the platform height but not the designated fall height (protective barrier height) for the equipment. Another common problem was failure to account for loss of impact absorption due to yearly degradation, resulting in tile installation without an adequate safety margin. Sixty nine percent of the artificial grass turf surfaces failed and it was found that foam layers with improper impact absorption characteristics for the height of the equipment were installed in many cases. Properly maintained loose fill materials of adequate depth tested very well, but results varied substantially between and within playgrounds, particularly in areas of heavy use (e.g., under swings, at the end of slides). Results indicated that maintenance of loose fill materials is an important determinant of their protective value.

Playground installers have not historically been required to complete surface impact testing, and most playground surfaces have been installed without any baseline testing. Once initial testing is carried out, ongoing routine testing should be completed because surfaces have a limited life span and impact absorption degrades over time. Such routine monitoring of surfaces is currently recommended by the CSA standards (CSA, 2014) but is not being required under Alberta regulations. There are feasibility issues associated with the implementation of such widespread testing as there are many child care facility playgrounds across the province and EPH lacks the funding and resources to complete all the initial and routine testing.

Costs associated with remediating failed playground surfaces have posed an additional challenge. Some child care facilities are nonprofit or do not have the funds to replace their playground surfacing. This constraint might cause disparities in safe playground access for children in lower socioeconomic status

Table 1. Number of each playground surface type tested per year and percentage passed.

\begin{tabular}{|l|c|c|c|c|c|c|c|c|}
\hline & $\mathbf{2 0 1 2}$ & $\mathbf{2 0 1 3}$ & $\mathbf{2 0 1 4}$ & $\mathbf{2 0 1 5}$ & $\mathbf{2 0 1 6}$ & Total tested & Total passed & $\begin{array}{c}\text { Percentage } \\
\text { passed (\%) }\end{array}$ \\
\hline Rubber tiles & 19 & 6 & 10 & 9 & 3 & 47 & 25 & 53 \\
\hline Pour-in-place surface & 1 & 1 & 13 & 0 & 14 & 29 & 20 & 69 \\
\hline Artificial grass turf & 3 & 8 & 3 & 2 & 0 & 16 & 5 & 31 \\
\hline Loose fill materials* & 3 & 2 & 2 & 0 & 3 & 10 & 7 & 70 \\
\hline Total & 26 & 17 & 28 & 11 & 20 & 102 & 57 & 56 \\
\hline
\end{tabular}

${ }^{*}$ Loose fill materials were pea gravel, wood fibre, or rubber crumb. 
neighborhoods. In some cases, facilities lacking funds have removed any elevated play structures and have implemented different types of play activities. Removal of elevated play structures is not the intended goal of surface impact testing, as EPH recognizes the importance of active outdoor play.

It is important to note the current 2014 CSA Standard is intended to be a threshold for life-threatening head injuries and not less severe but still significant injuries such as broken limbs or concussions. Current limits that were originally based on research done by the Automotive Industry in the 1960s and 1970s and then adopted by the Consumer Product Safety Commission to become the thresholds for playground standards may be outdated (Huber, 2011). In 2000, new and more conservative threshold values were set by the National Highway Traffic Safety Administration, and playground standards have not been updated to recognize advances in research on injury prevention (Huber, 2011). Evidence supports reducing thresholds in standards to a HIC of 700 for play structures intended for children 5-12 years old, 570 for play structures for children 2-5 years old, and to a Gmax value of 105 (Huber, 2011). The risk of injury has been estimated to be 1.8 times greater when Gmax is 150-199 compared with $<150$ (Laforest et al., 2001), providing further evidence for lowering Gmax levels in playground safety standards. Affected parties should be aware of this possible change because many more playgrounds will fail impact absorption tests if standards become more stringent, and all playgrounds in Alberta will need to be re-evaluated. Manufacturers of playground surfacing will also need to re-evaluate and retest their materials to ensure they meet new standards.

\section{Future directions}

Almost half of the child care facility playgrounds in AHS Calgary Zone are failing surface impact absorption tests. These results could likely be extrapolated to the rest of Alberta and to other Canadian jurisdictions. Although playground equipment that engages and provides developmentally appropriate challenges to children may never be entirely without risk (Martin and Cooper, 2005), the burden of injury associated with playground falls warrants greater attention. Many studies support the conclusion that injury risk is greater for playgrounds that do not meet existing standards (MacKay, 2003; Macpherson et al., 2010).

EHOs can play an important role in playground safety by developing and disseminating information on playground surfacing to playground owners/operators so that informed choices can be made prior to installing a playground surface. Information should include choosing acceptable surfacing materials, sourcing a reputable company to purchase and install surfacing, obtaining acceptable documentation of surfacing materials including lab test data, determining installation requirements, and securing life expectancy and maintenance information from the manufacturer (surfacing requires maintenance and degrades, requiring periodic replacement).

Formal assessment of playgrounds, in particular playground surfacing, should be considered in future legislation that governs playgrounds and children's safety. Given the multiple challenges involved in scaling up the EPH role in playground surfacing assessment, it would be preferable for playground safety requirements to be developed that place the responsibility on the owner/operator to ensure that playground surfacing is adequate. This could involve requiring owners/operators to provide initial installation surface impact test data from the installer as well as independent routine surface impact testing for existing playgrounds on a prescribed frequency. Child injury prevention is an established role of EPH, and more needs to be done to address inconsistencies in surfacing requirements across Canada.

\section{References}

Alberta Health, Health System Accountability and Performance, Surveillance and Assessment Branch. 2016. Playground injuries. Unpublished raw data.

American Society for Testing and Materials. 2013. Standard specification for impact attenuation of surfacing materials within the use zone of playground equipment. ASTM F1292-13. West Conshohocken, PA: ASTM International.

Briss, P.A., Sacks, J.J., Addiss, D.G., Kresnow, M., and O’Neil, J. 1995. Injuries from falls on playgrounds. Arch Pediatr Adolesc Med. 149: 906-911. doi: 10.1001/archpedi.1995.02170210080014

Canadian Standards Association (CSA). 2014. Children's playspaces and equipment. CAN/CSA-Z614-14. Mississauga, ON: Canadian Standards Association Group.

Cheng, T.A., Bell, J.M., Haileyesus, T., Gilchrist, J., Sugerman, D.E., and Coronado, V.G. 2016. Nonfatal playground-related traumatic brain injuries among children, 2001-2013. Pediatrics. 137(6): e20152721. https://doi.org/10.1542/peds.2015-2721

Fuselli, P., and Yanchar, N.L. 2012. Position statement-Preventing playground injuries. Canadian Paediatric Society. Available at: http://www.cps.ca/documents/position/playground-injuries [accessed 21 December 2016].

Gunatilaka, A.H., Sherker, S. and Ozanne-Smith,J. 2004. Comparative performance of playground surfacing materials including conditions of extreme non-compliance. Inj. Prev. 10: 174-179. doi: 10.1136/ ip.2003.004010

Howard, A.W., Macarthur, C., Rothman, L., Willan, A., and Macpherson, A.K. 2009. School playground surfacing and arm fractures in children: A cluster randomized trial comparing sand to wood chip surfaces. PLoS Med. 6(12): e1000195 doi: 10.1371/ journal.pmed.1000195

Huber, R. 2011. Impact attenuation values and prevention of head injuries in children's playgrounds. Available at: http://www.playgroundadvisory.com/publications/Articles/Impact $\% 20$ Attenution\%20Values\%20\&\%20Prevention\%20of\%20Head\%20 Injuries\%20in\%20Playgrounds\%2014-8-11.pdf [accessed 21 December 2016].

Laforest, S., Robitailee, Y., Lesage, D. and Dorval, D. 2001. Surface characteristics, equipment height, and the occurrence and severity of playground injuries. Inj. Prev. 7: 35-40. doi: 10.1136/ip.7.1.35

MacKay, M. 2003. Playground injuries. Inj. Prev. 9: 194-196. doi: 10.1136/ip.9.3.194

Macpherson, A.K., Jones, J., Rothman, L., Macarthur, C. and Howard, A.W. 2010. Safety standards and socioeconomic disparities in school playground injuries: A retrospective cohort study. BMC Public Health. 10: 542-546 https://doi.org/10.1186/14712458-10-542

Martin, J. and Cooper, C.D. 2005. Playground safety in south western Sydney. J. Paediatr. Child Health. 41: 587-591. doi: 10.1111/j. 1440-1754.2005.00727.x

United Nations General Assembly. 1989. Convention on the rights of the child. Available at: http://www.ohchr.org/EN/ProfessionalInterest/ Pages/CRC.aspx [accessed 30 December 2016]. 